\title{
Climatological circulation in Lake Michigan
}

\author{
Dmitry Beletsky ${ }^{1}$ and David Schwab ${ }^{2}$ \\ Received 22 August 2008; revised 7 October 2008; accepted 10 October 2008; published 11 November 2008.
}

[1] Maps of climatological circulation in Lake Michigan are presented for the first time. They are based on ten years continuous modeling of lake hydrodynamics from 1998 2007 using observed meteorological data as the forcing function. Model results show a remarkably stable largescale cyclonic circulation pattern during both stratified and unstratified conditions. Lake-averaged mean current speed is about $2 \mathrm{~cm} / \mathrm{s}$, but currents can reach $10 \mathrm{~cm} / \mathrm{s}$ in some locations. The model results are confirmed by long-term current observations. Citation: Beletsky, D., and D. Schwab (2008), Climatological circulation in Lake Michigan, Geophys. Res. Lett., 35, L21604, doi:10.1029/2008GL035773.

\section{Introduction}

[2] Reliable information on long-term circulation patterns in the Great Lakes in general and Lake Michigan in particular is sorely needed for a variety of issues ranging from water quality predictions to sediment transport and ecosystem modeling. Since the pioneering drift bottle study carried by Harrington [1894], only fragmentary data obtained in the course of several multi-disciplinary programs have been available for this purpose. In the course of the Lake Michigan Mass Balance Study (LMMBS), Beletsky et al. [1999] summarized lake-wide 1982-83 observations to obtain the first maps of seasonal circulation in Lake Michigan. The associated modeling effort proved to be quite successful in reproducing a large-scale cyclonic circulation pattern observed in 1982-83. A rather similar pattern was predicted by the model for 1994-95 as well [Beletsky and Schwab, 2001]. At the same time, modeling for the years 1998-2003 conducted in the course of the Episodic Events - Great Lakes Experiment (EEGLE), followed by a larval fish transport study revealed substantial variability of summer circulation on the scale of 1-3 months [Beletsky et al., 2006, 2007]. More recently, the 2004-2007 lake circulation was modeled for a project funded by the Oceans and Human Health Initiative (NOAA). With the latest phase of modeling just completed, we are now in a position to produce, for the first time in the history of Great Lakes, a map of the climatological circulation in Lake Michigan based on 10 continuous years of model output (1998-2007). The chosen period of study corresponds to a current warm climate with little ice on the lake in winter [Assel, 2005], which allowed us to disregard the effect of ice in the model.

\footnotetext{
${ }^{1}$ Cooperative Institute for Limnology and Ecosystems Research, School of Natural Resources and Environment, University of Michigan, Ann Arbor, Michigan, USA.

${ }^{2}$ Great Lakes Environmental Research Laboratory, NOAA, Ann Arbor, Michigan, USA.
}

Copyright 2008 by the American Geophysical Union. 0094-8276/08/2008GL035773

\section{Methods}

[3] A 3-dimensional circulation model of Lake Michigan [Beletsky and Schwab, 2001] is used to calculate lake circulation and thermal structure in $1998-2007$ on a $2 \mathrm{~km}$ grid. The model is based on the Princeton Ocean Model of Blumberg and Mellor [1987]. The hydrodynamic model of Lake Michigan has 20 vertical levels with finer spacing near the surface and the bottom. Interannual variability of water level in the lake is not included. Momentum and heat fluxes are derived from hourly meteorological observations (wind speed and direction, air temperature, dew point and cloud cover) obtained from about 20-30 National Weather Service stations around Lake Michigan and NOAA buoys 45002 and 45007 in 1998-2007. Details of heat and momentum flux calculations are presented by Beletsky and Schwab [2001] and Beletsky et al. [2003].

\section{Climatological Circulation}

[4] Lake Michigan experiences seasonal stratification for about half a year, roughly from May until November. Therefore, we averaged model output (depth-averaged currents) over two 6 month periods: May-October ("summer") and November-April ("winter"). Annual circulation represents a 10-year average. A similar type of averaging was adopted in previous studies of circulation in Lake Michigan [Beletsky et al., 1999; Beletsky and Schwab, 2001].

[5] Modeled large-scale summer circulation is cyclonic (Figure 1) except for narrow areas in the southernmost and northernmost parts of the lake where a weak anticyclonic circulation persists. Mean depth-averaged current speed is $1.9 \mathrm{~cm} / \mathrm{s}$, and maximum speed is $9.3 \mathrm{~cm} / \mathrm{s}$. Several medium size cyclonic and anticyclonic gyres are visible in the middle of the lake tightly connected to the complex bathymetry of a mid-lake ridge. Winter circulation is stronger than summer circulation and is more cyclonic in the southern basin but less so near the entrance to the Green Bay. An anticyclonic gyre in the northernmost part of the lake is more pronounced in winter than in summer. On the contrary, the summertime anticyclonic gyre in the southernmost part of the lake is replaced by a strong cyclonic circulation in winter. Mean winter current speed is $2.5 \mathrm{~cm} / \mathrm{s}$, and maximum speed is $10.3 \mathrm{~cm} / \mathrm{s}$. Because winter circulation is stronger than summer circulation, annual circulation closely resembles winter circulation. Mean annual current speed is $2.1 \mathrm{~cm} / \mathrm{s}$, and maximum speed is $9.1 \mathrm{~cm} / \mathrm{s}$. Mean current speed in the model is close to the 1982-83 measurements reported by Beletsky et al. [1999] giving $1.3 \mathrm{~cm} / \mathrm{s}$ for summer, $2.4 \mathrm{~cm} / \mathrm{s}$ for winter, and $1.9 \mathrm{~cm} / \mathrm{s}$ for annual observed current speeds.

[6] Interannual variability of the main atmospheric and lake parameters is shown in Table 1. Lake surface temperature closely follows the $2^{\circ} \mathrm{C}$ fluctuations in atmospheric 

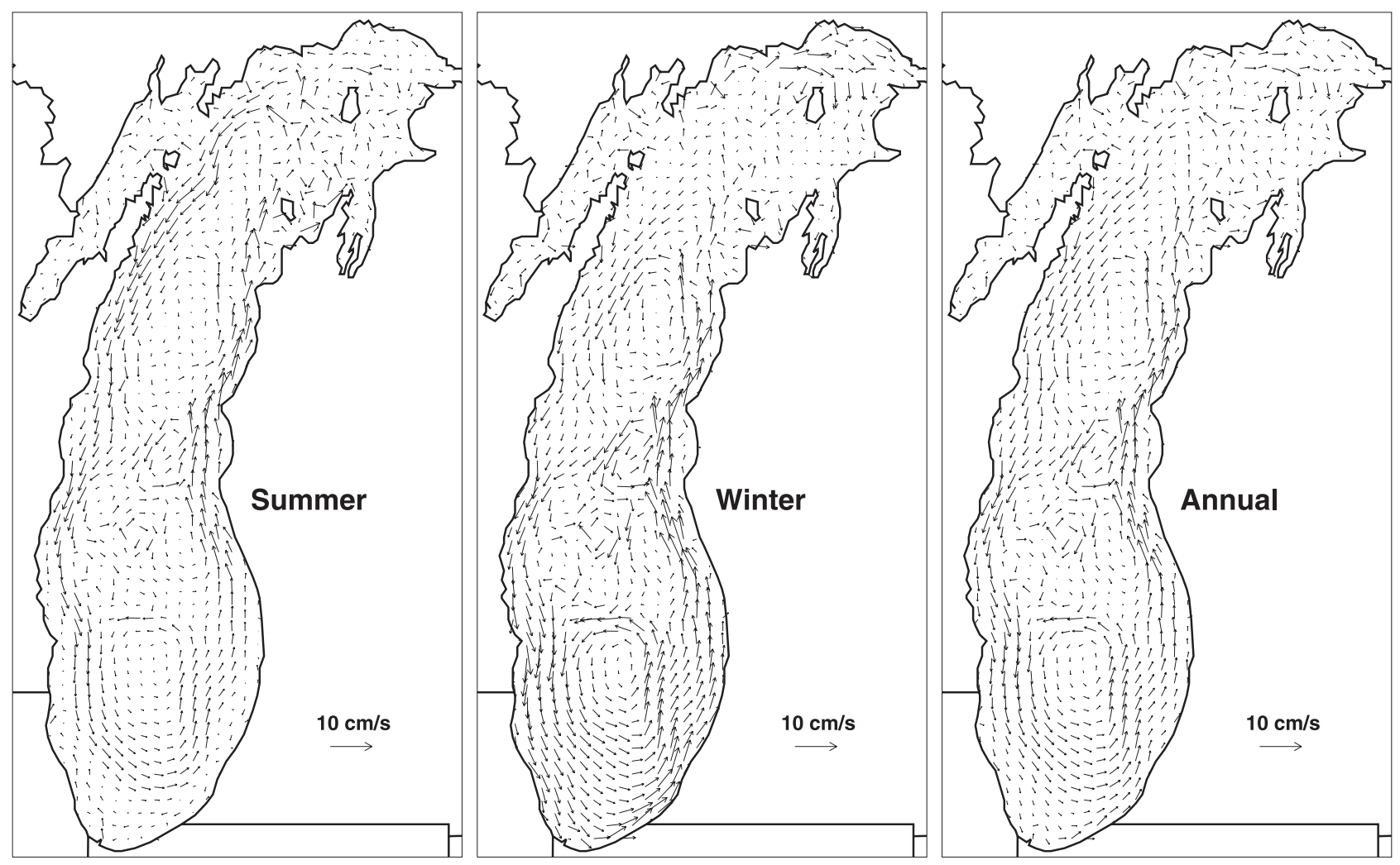

Figure 1. Modeled mean 1998-2007 summer, winter, and annual depth-averaged circulation in Lake Michigan.

temperature with an amplitude of about $1.5^{\circ} \mathrm{C}$. Lake-averaged temperature follows the same pattern (with exception of the first couple of years during the model thermal "spin-up"), but the amplitude of the signal is reduced to about $1^{\circ} \mathrm{C}$. Wind speed and direction (which is westerly) do not exhibit significant variability. The speed of mean currents stays rather flat until the very end of the 10 -year period, when it begins to gradually increase by about $30 \%$. We don't have an explanation for the increase at this time, but we plan to examine this issue in a future publication on the interannual variability of lake circulation.

\section{Model Validation}

[7] The most useful data set of long-term current measurements that is available for model validation was obtained during the EEGLE experiment [Rao et al., 2004]. Although a significant number of current meters were used, they were deployed in a relatively small area in the southeast corner of Lake Michigan. Also, because of EEGLE's focus on winter dynamics, the best coverage was during the three winters in 1998-2000, although some current data were collected in summer of 1998 as well (no ADCP measurements though). All these data were averaged over the same 6 month periods (May-October and November-April) for comparison with model results. In 1998, winter currents were averaged for the January-April period only since the model run started on January 1.

[8] Most EEGLE data were obtained with two vectoraveraging current meters (VACM) per mooring, one at $12 \mathrm{~m}$ below the surface and another $1 \mathrm{~m}$ above the bottom. Mooring depths range from 20 to $60 \mathrm{~m}$. Although lake currents are rather uniform with depth in winter, nearbottom VACM measurements typically show much smaller speeds because they were taken in the logarithmic friction layer. Therefore, they are shown primarily for validation of current direction, not current speed. Besides, in some winters they provide the majority of spatial coverage (in 1999 all subsurface current meters failed). In addition to VACM, between four and seven ADCPs were deployed each winter as well, and they provide the most appropriate data for comparison with depth-averaged currents from the 3D model.

Table 1. Main Atmospheric and Lake Parameters Averaged Annually for $1998-2007^{\mathrm{a}}$

\begin{tabular}{|c|c|c|c|c|c|c|c|c|c|c|}
\hline & 1998 & 1999 & 2000 & 2001 & 2002 & 2003 & 2004 & 2005 & 2006 & 2007 \\
\hline $\mathrm{AT},{ }^{\circ} \mathrm{C}$ & 10.2 & 9.1 & 8.7 & 8.8 & 9.1 & 7.9 & 8.5 & 9.5 & 9.5 & 9.1 \\
\hline $\mathrm{WS}, \mathrm{m} / \mathrm{s}$ & 6.7 & 6.8 & 6.7 & 6.6 & 7.1 & 6.9 & 6.9 & 6.6 & 6.5 & 6.6 \\
\hline WD, deg & 290 & 275 & 285 & 259 & 270 & 298 & 276 & 289 & 289 & 260 \\
\hline $\mathrm{SPM}, \mathrm{cm} / \mathrm{s}$ & 2.1 & 1.8 & 1.9 & 2.0 & 1.9 & 2.0 & 2.0 & 2.3 & 2.7 & 2.6 \\
\hline $\mathrm{WT},{ }^{\circ} \mathrm{C}$ & 6.6 & 6.7 & 6.8 & 6.4 & 6.8 & 5.9 & 6.3 & 6.7 & 6.9 & 6.5 \\
\hline $\mathrm{SST},{ }^{\circ} \mathrm{C}$ & 11.3 & 10.9 & 10.6 & 10.5 & 10.9 & 9.7 & 10.1 & 11.3 & 11.2 & 11.1 \\
\hline
\end{tabular}

${ }^{\mathrm{a}} \mathrm{AT}$, air temperature; WS, wind speed; WD, wind direction; SPM, speed of mean currents; WT, water temperature (volume averaged); SST, surface water temperature. 

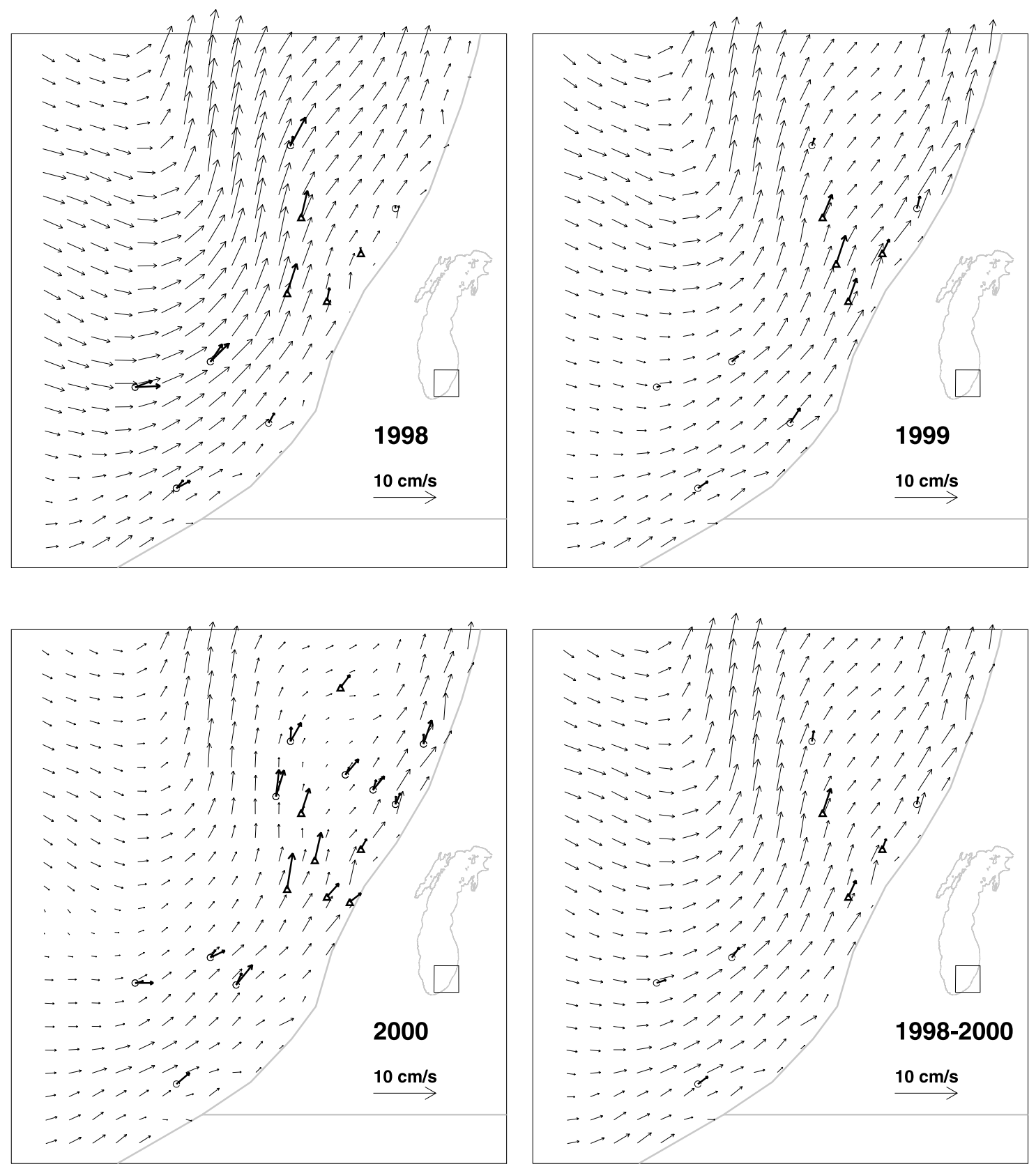

Figure 2. Modeled depth-averaged circulation in individual winters (1998-2000), and three-winter mean. Triangles denote ADCP moorings and open circles denote VACM moorings. Observations are shown with thick arrows. ADCP measurements are depth-averaged. In case of VACM measurements larger arrows represent 12 m measurements and smaller arrows represent near-bottom measurements (in 1999 only near-bottom measurements are available).

[9] As was previously shown by Rao et al. [2004], cyclonic circulation dominated the south-east area of Lake Michigan during the 1998-2000 winters, exhibiting relatively little interannual variability. Mean current speed measured at ADCP locations increased from $3.1 \mathrm{~cm} / \mathrm{s}$ in 1998 to $3.7 \mathrm{~cm} / \mathrm{s}$ in 1999 and dropped slightly to $3.4 \mathrm{~cm} / \mathrm{s}$ in 2000. Depth-averaged current speed typically increases offshore, and currents follow isobaths very closely, similar to mean circulation observed on the inner shelf of the Middle Atlantic Bight, which has comparable size and depth [Lentz, 2008].

[10] Comparison with observations showed remarkable model skill in predicting long-term winter currents in Lake
Michigan (Figure 2). Not only was the flow direction predicted extremely accurately (mean directional error at ADCP locations was only 21,6 , and 10 degrees in 1998 , 1999, and 2000 respectively), but the current speed as well. Following temporal trend seen in observations, mean model speed at ADCP locations increased from $3.7 \mathrm{~cm} / \mathrm{s}$ in 1998 to $3.9 \mathrm{~cm} / \mathrm{s}$ in 1999 and dropped to $2.4 \mathrm{~cm} / \mathrm{s}$ in 2000 . The biggest discrepancy occurred in 2000 when the model underestimated currents in the ADCP moorings area. The three-winter average (1998-2000) model circulation shows good comparison with observations, increasing our confidence in climatological model results. 


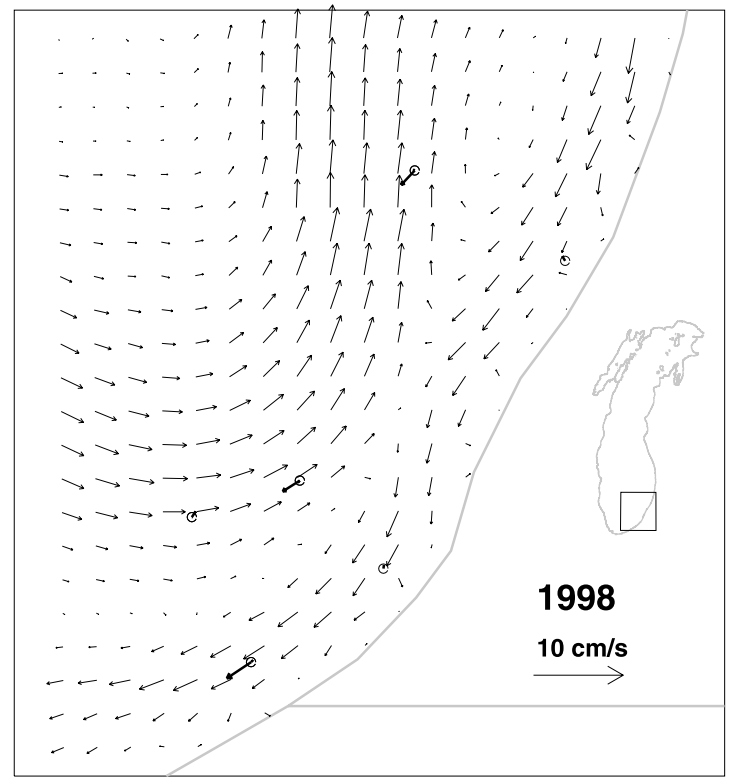

Figure 3. Mean depth-averaged summer circulation in (left) 1998 and (right) 1999. Observations at $12 \mathrm{~m}$ are shown with thick arrows.

[11] Summer circulation was simulated less accurately than winter circulation (Figure 3 (left)), in agreement with our earlier findings [Beletsky and Schwab, 2001]. Although the speed of modeled summer currents is within the range of the speed of observed ones, the anticyclonic nearshore gyre was much less pronounced in the model than in observations, leading to discrepancies in offshore circulation. This is most likely a result of underestimation of characteristic anticyclonic vorticity in the wind stress during a period of stratification (Figure 4), which determines the size and position of an anticyclonic gyre in the southern basin. It is interesting to note that in 1999 (when the anticyclonic wind stress vorticity was twice as strong as in 1998) the summer anticyclonic gyre occupied a much larger area in the model

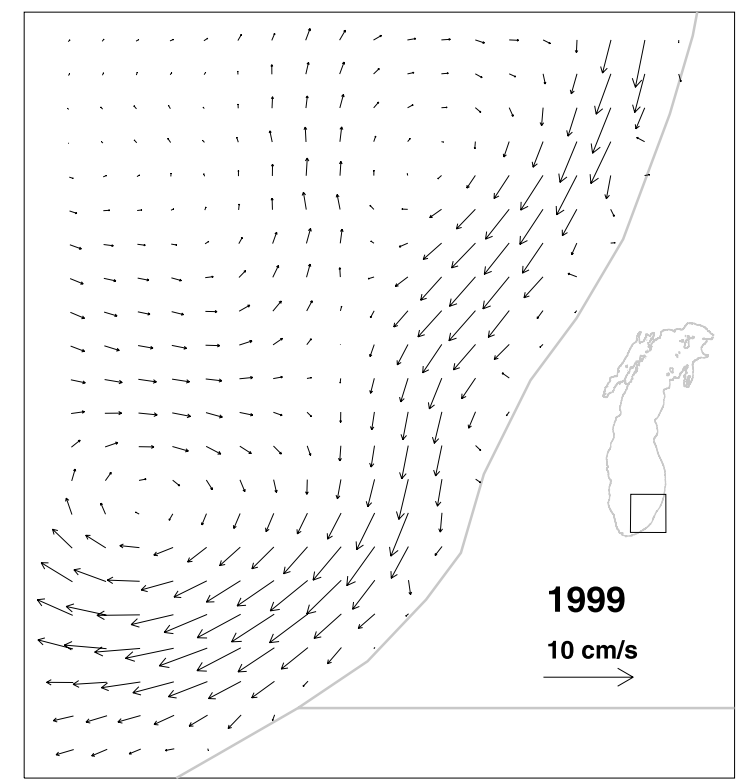

(Figure 3 (right)), resembling 1998 observations more closely.

[12] The current meter data presented here are not sufficient for a rigorous model validation, but based on previous experience, we feel that more extensive current meter data, both spatially and temporally, would provide similar results. Hopefully, more extensive permanent observation stations could provide this data in the future.

\section{Discussion and Conclusions}

[13] The mean lake-wide 1998-2007 circulation was cyclonic in both stratified and unstratified periods, a remarkable fact in itself because lake currents show signifi-
January-April 1998

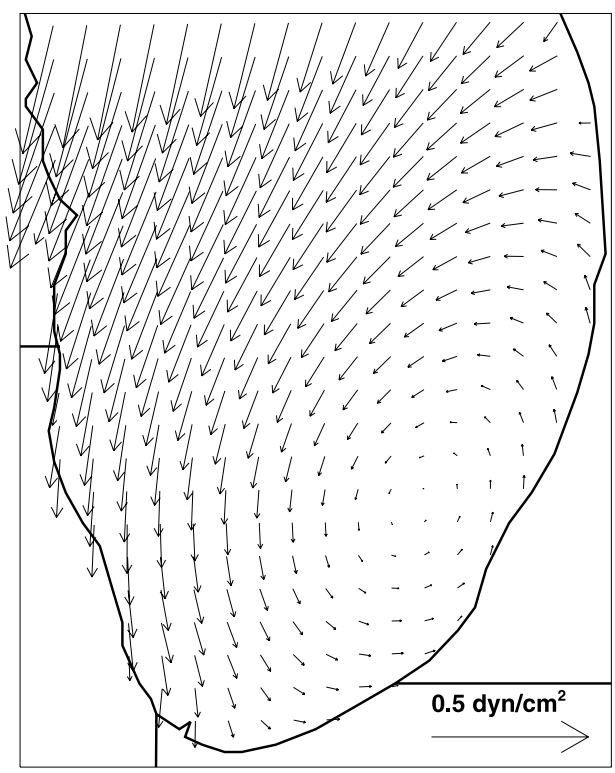

May-October 1998

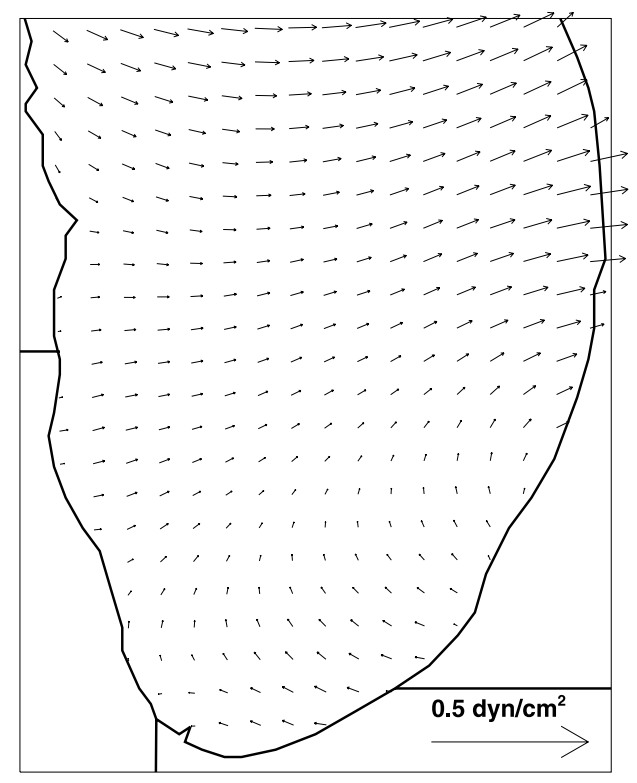

Figure 4. Calculated mean wind stress over southern Lake Michigan in 1998. 
cant variability on a daily, weekly, and even monthly scale [Beletsky and Schwab, 2001; Beletsky et al., 2006, 2007]. We also suggest that presented climatological summer circulation is representative of conditions extending well beyond the 1998-2007 period. Thus, the 1982-83 data show a similar cyclonic lake-wide circulation with similar current speeds [Beletsky et al., 1999]. Moreover, a century old set of (Lagrangian) observations obtained by Harrington [1894] in 1892-93 showed cyclonic circulation in summer as well.

[14] As recently shown by Schwab and Beletsky [2003], cyclonic circulation is mostly supported by density gradients in summer. Cyclonic summer circulation yields to an anticyclonic circulation only in some limited shallow areas (like the southern most part of the lake) driven by a characteristic anticyclonic vorticity in the wind stress in the mesoscale atmospheric circulation system (Figure 4). Such lake-induced mesoscale circulation systems occur because of the size of Lake Michigan and its considerable heat capacity, generating a mesohigh in the summer [Lyons, 1971] and a mesolow in the winter [Pettersen and Calabrese, 1959; Weiss and Sousounis, 1999].

[15] In the warm, largely ice-free winters between 19982007 , circulation was cyclonic as well, which was also seen in 1982-83 winter observations conducted during one of the warmest winters of the 20th century. This circulation is driven by the cyclonic vorticity in the wind stress [Schwab and Beletsky, 2003] in a characteristic mesolow atmospheric circulation system (Figure 4).

[16] Although qualitatively similar, both summer, winter, and annual current speeds are $50-100 \%$ higher than in previous $5 \mathrm{~km}$ grid LMMBS model runs for 1982-83 and 1994-95 [Beletsky and Schwab, 2001]. Since the same type of wind data was used for all simulations, this is likely a result of increased horizontal resolution and possibly also increased wind speed over the Great Lakes over the last three decades [Austin and Colman, 2007].

[17] In addition, we note that in a colder climate, with longer ice duration and increased spatial ice extent, the winter circulation pattern may change because additional wind stress vorticity should be generated due to the difference in the surface drag over ice and open water, therefore additional research is needed to look into cold climate climatology.

[18] The implications of the presented circulation patterns on the lake's geology, chemistry and biology could be significant. Many authors report persistent nearshore offshore gradients in nutrients and productivity [Vanderploeg et al., 2007; Johengen et al., 2008; Kerfoot et al., 2008], which is consistent with regular, isobath-following currents in most parts of the lake (Figure 1). Also, mean cyclonic circulation in the southern basin facilitates counterclockwise transport of fine-grained sediments (and attached contaminants) along the southern shoreline, from erodible bluffs on the west coast to the place of their burial in the southeastern area of the lake [Eadie et al., 2002].
[19] Acknowledgments. This work was funded by the NOAA CSCOR, Great Lakes Fishery Trust, and the NOAA's Oceans and Human Health Initiative. We thank anonymous reviewers for comments that improved the paper. This is GLERL contribution 1485.

\section{References}

Assel, R. A. (2005), Classification of annual Great Lakes ice cycles: Winters of 1973-2002, J. Clim., 18, 4895-4905.

Austin, J. A., and S. M. Colman (2007), Lake Superior summer water temperatures are increasing more rapidly than regional air temperatures: A positive ice-albedo feedback, Geophys. Res. Lett., 34, L06604, doi:10.1029/2006GL029021.

Beletsky, D., and D. J. Schwab (2001), Modeling circulation and thermal structure in Lake Michigan: Annual cycle and interannual variability, J. Geophys. Res., 106, 19,745-19,771.

Beletsky, D., J. H. Saylor, and D. J. Schwab (1999), Mean circulation in the Great Lakes, J. Great Lakes Res., 25, 78-93.

Beletsky, D., D. J. Schwab, P. J. Roebber, M. J. McCormick, G. S. Miller, and J. H. Saylor (2003), Modeling wind-driven circulation during the March 1998 sediment resuspension event in Lake Michigan, J. Geophys. Res., 108(C2), 3038, doi:10.1029/2001JC001159.

Beletsky, D., D. J. Schwab, and M. McCormick (2006), Modeling the 1998-2003 summer circulation and thermal structure in Lake Michigan, J. Geophys. Res., 111, C10010, doi:10.1029/2005JC003222.

Beletsky, D., D. Mason, D. J. Schwab, E. Rutherford, J. Janssen, D. Clapp, and J. Dettmers (2007), Biophysical model of larval yellow perch advection and settlement in Lake Michigan, J. Great Lakes Res., 33, 842-866.

Blumberg, A. F., and G. L. Mellor (1987), A description of a threedimensional coastal ocean circulation model, in Three Dimensional Ocean Models, Coastal Estuarine Sci., vol. 4, edited by N. S. Heaps, pp. 1-16, AGU, Washington, D. C.

Eadie, B. J., et al. (2002), Particle transport, nutrient cycling, and algal community structure associated with a major winter-spring sediment resuspension event in southern Lake Michigan, J. Great Lakes Res., $28,324-337$.

Harrington, M. W. (1894), Currents of the Great Lakes as Deduced From the Movements of Bottle Papers During the Seasons of 1892 and 1893, U. S. Weather Bur., Washington, D. C.

Johengen, T. H., B. A. Biddanda, and J. B. Cotner (2008), Stimulation of Lake Michigan plankton metabolism by sediment resuspension and river runoff, J. Great Lakes Res., 34, 213-227.

Kerfoot, W. C., J. W. Budd, S. A. Green, J. B. Cotner, B. A. Biddanda, D. J. Schwab, and H. A. Vanderploeg (2008), Doughnut in the desert: Latewinter production pulse in southern Lake Michigan, Limnol. Oceanogr, 53, 589-604.

Lentz, S. (2008), Observations and a model of the mean circulation over the Middle Atlantic Bight continental shelf, J. Phys. Oceanogr., 6, $1203-$ 1221.

Lyons, W. A. (1971), Low level divergence and subsidence over the Great Lakes in summer, paper presented at the 14th Conference of Great Lakes Research, pp. 467-487, Int. Assoc. Great Lakes Res., Ann Arbor, Mich. Pettersen, S., and P. A. Calabrese (1959), On some weather influences due to warming of the air by the Great Lakes in winter, J. Meteorol., 16, 646652.

Rao, Y. R., M. J. McCormick, and C. R. Murthy (2004), Circulation during winter and northerly storm events in southern Lake Michigan, J. Geophys. Res., 109, C01010, doi:10.1029/2003JC001955.

Schwab, D. J., and D. Beletsky (2003), Relative effects of wind stress curl, topography, and stratification on large-scale circulation in Lake Michigan, J. Geophys. Res., 108(C2), 3044, doi:10.1029/2001JC001066.

Vanderploeg, H. A., et al. (2007), Anatomy of the recurrent coastal sediment plume in Lake Michigan and its impacts on light climate, nutrients, and plankton, J. Geophys. Res., 112, C03S90, doi:10.1029/2004JC002379. Weiss, C. C., and P. J. Sousounis (1999), A climatology of collective lake disturbances, Mon. Weather Rev., 127, 565-574.

D. Beletsky, Cooperative Institute for Limnology and Ecosystems Research, School of Natural Resources and Environment, University of Michigan, 2205 Commonwealth Boulevard, Ann Arbor, MI 48105, USA. (dima.beletsky@noaa.gov)

D. Schwab, Great Lakes Environmental Research Laboratory, NOAA, 2205 Commonwealth Boulevard, Ann Arbor, MI 48105, USA. (david. schwab@noaa.gov) 